\title{
Superhydrophobic Properties of Nanotextured Polypropylene Foils Fabricated by Roll- to-Roll Extrusion Coating
}

Telecka, Agnieszka; Murthy, Swathi; Sun, Ling; Pranov, Henrik; Taboryski, Rafael J.

Published in:

ACS Macro Letters

Link to article, DOI:

10.1021/acsmacrolett.6b00550

Publication date:

2016

Document Version

Peer reviewed version

Link back to DTU Orbit

Citation (APA):

Telecka, A., Murthy, S., Sun, L., Pranov, H., \& Taboryski, R. J. (2016). Superhydrophobic Properties of

Nanotextured Polypropylene Foils Fabricated by Roll-to-Roll Extrusion Coating. ACS Macro Letters, 5(9), 10341038. https://doi.org/10.1021/acsmacrolett.6b00550

\section{General rights}

Copyright and moral rights for the publications made accessible in the public portal are retained by the authors and/or other copyright owners and it is a condition of accessing publications that users recognise and abide by the legal requirements associated with these rights.

- Users may download and print one copy of any publication from the public portal for the purpose of private study or research.

- You may not further distribute the material or use it for any profit-making activity or commercial gain

- You may freely distribute the URL identifying the publication in the public portal 
Superhydrophobic properties of nanotextured polypropylene foils fabricated by roll-to-roll extrusion coating

Agnieszka Telecka ${ }^{1}$, Swathi Murthy ${ }^{2,3}$, Ling Schneider ${ }^{1}$, Henrik Pranov ${ }^{3}$, and Rafael Taboryski ${ }^{*}{ }^{1}$

${ }^{1}$ Department of Micro- and Nanotechnology, Technical University of Denmark, 2800 Kongens Lyngby, Denmark

${ }^{2}$ Department of Photonics Engineering, Technical University of Denmark, Frederiksborgvej 399, DK-4000 Roskilde, Denmark

${ }^{3}$ Inmold A/S, Gregersensvej 6H, DK-2630 Taastrup, Denmark

* rata@nanotech.dtu.dk

\begin{abstract}
We demonstrate the use of roll-to-roll extrusion coating (R2R-EC) for fabrication of nanopatterned polypropylene (PP) foils with strong anti-wetting properties. The anti-wetting nanopattern is originated from textured surfaces fabricated on silicon wafers by a single-step method of reactive ion etching with different processing gas flow rates. We provide a systematic study of the wetting properties for the fabricated surfaces and show that a controlled texture stretching effect in the R2R-EC process is instrumental to yield the superhydrophobic surfaces with water contact angles approaching $160^{\circ}$ and droplet roll-off angles below $10^{\circ}$.
\end{abstract}


Technologies for fabrication of biomimetic surfaces with superhydrophobic properties have gained considerable attention, ${ }^{1,2}$ due to the broad range of applications such as solar cells, ${ }^{3}$ self-cleaning fabrics, ${ }^{4}$ anti-reflective, anti-fogging, ${ }^{5,6}$ and anti-ice materials. ${ }^{7}$ In nature, the superhydrophobic effect aka the lotus effect is mostly known from plant leafs ${ }^{8}$, but is also encountered in fauna, e.g. the water strider Notonecta glauca $^{9,10}$. Fabrication of superhydrophobic materials usually require initial structuring with a hierarchical micro and nanopattern to increase surface roughness, ${ }^{11,12}$ and a subsequent coating with low surface energy chemistry ${ }^{13,14}$. The surface coating does however represent at least one extra fabrication step and is best suited for coating of solid surfaces, such as that of Si with perfluorodecyltrichlorosilane (FDTS). ${ }^{15}$ Enabling direct large-area surface texturing of intrinsically hydrophobic thermoplastics would be more feasible and lower the barrier for use of superhydrophobic materials for e.g. self-cleaning applications.

Among technologies for large-area nanotexturing, roll-to-roll (R2R) UV-assisted nanoimprint lithography is the most established. It was originally demonstrated by Ahn et $\mathrm{al}^{16,17}$ and more recently by Leitgeb et al. with even faster roller speed in excess of $10 \mathrm{~m} / \mathrm{min}$ on a $25 \mathrm{~cm}$ wide web. ${ }^{18}$ This R2R method is feasible for nanostructuring but is limited with regard to surface chemistry, as the relief must be formed in a UVcurable resin. John et al. demonstrated R2R nanoimprinting using perfluoropolyether (PFPE) composite molds ${ }^{19}$, while Li et al. reported production of large area flexible biomimetic surfaces using a R2R UVassisted nanoimprint process ${ }^{20}$. The method employed by $\mathrm{Li}$ et al. requires steps of photocuring of the structured layer and coating. Moreover it runs at modest line-speed of $10 \mathrm{in} / \mathrm{min}(\sim 0.25 \mathrm{~m} / \mathrm{min})$ with web width of 6 in ( 150 mm). A R2R method for production of large area superhydrophobic surfaces should preferably have much higher productivity and allow structuring of common inexpensive and intrinsically hydrophobic polymers such as polyethylene, ${ }^{21}$ cyclic olefin copolymer, ${ }^{22}$ or polypropylene (PP) ${ }^{23}$ to gain practical relevance. An ideal material is isotactic PP, which has good hydrophobic properties (see Table S1), has low surface energy and is inexpensive. ${ }^{24}$ 
In this paper we report on R2R extrusion coating (R2R-EC), as sketched in Figure 1a, for the manufacture of superhydrophobic surfaces in PP. In R2R-EC, the polymer melt curtain is extruded through a flat nozzle, then laminated onto a carrier foil by squeezing the melt between a cooling roller and a counter roller, and finally collected on a wind-up roller. In a previous publication, we demonstrated this method for replication of nanopillar structures in PP. ${ }^{25}$ R2R-EC is well established and widely used in the packaging industry for large scale fabrication of smooth polymer films. However, to the best of our knowledge, nanotexturing of surfaces with biomimetic functionalities produced with R2R-EC has not yet been reported.
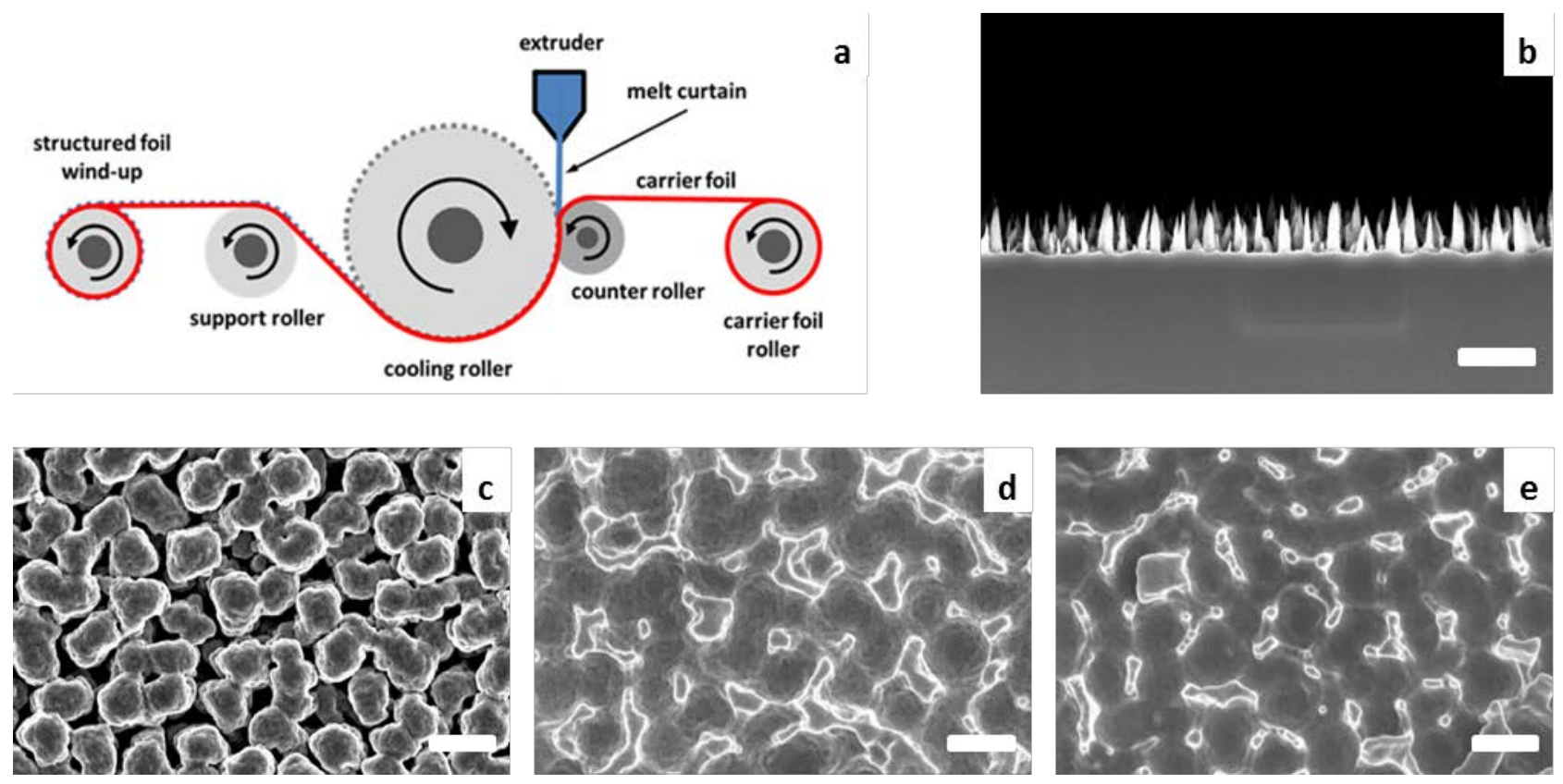

Fig.1 (a) Schematic representation of R2R EC process. (b) SEM image of the nanograss master features fabricated on Si wafer with the 70-70 process, cross section. (c) SEM image of the corresponding mold (7070), top view. (d) SEM image, top view of PP foil with 70-70 replicated pattern, $T_{C}=70^{\circ}, V_{R}=20 \mathrm{~m} / \mathrm{min}$. (e) SEM image, top view of PP foil with 70-70 replicated pattern, $T_{C}=70^{\circ}, V_{R}=60 \mathrm{~m} / \mathrm{min}$. Scale bars for figures (b), (c), (d), and (e) are all $1 \mu \mathrm{m}$. 
For the master structure, we use a Si nanograss texture. ${ }^{26}$ The nanograss was originated in Si by reactive ion etching (RIE). RIE can be used for maskless texturing of silicon surfaces through the combined effect of a corrosive gas $\left(\mathrm{SF}_{6}\right.$ and/or $\left.\mathrm{CH}_{4}\right)$ and a passivating gas $\left(\mathrm{O}_{2}\right) \cdot{ }^{27-31}$ Surfaces made this way predominantly appear black due to the scattering of the incident light by the surface texture. Hence, the texture is also known as "black silicon", and has widely been used for optical anti-reflective surfaces. ${ }^{27,}{ }^{30,31}$ By tuning the processing parameters, it is possible to alter the structure shape. ${ }^{32}$ The processing parameters used are shown in the Supplementary Information, Table S2. In this study all parameters were kept constant except for the oxygen gas flow rate, which was varied in order to optimize functionality. For simplicity, we denote samples of different $\mathrm{SF}_{6}$ and $\mathrm{O}_{2}$ flow rates as $Q_{S F_{6}}-Q_{O_{2}}$. Therefore 70-70 means a sample processed with $Q_{S F_{6}}=70$ $\mathrm{sccm}$, and $Q_{O_{2}}=70 \mathrm{sccm}$. The Si master structure was transferred to a Ni mold by electroforming a negative relief texture on top of the textured Si wafers. After removal of the Si by etching in potassium hydroxide, the Ni counterparts were attached to the cooling roller and used as molds for the replication step. The whole process sequence is sketched in Figure S1 while SEM pictures of the Ni molds are shown in Figure S2. Figure $1 \mathbf{b}$ shows a scanning electron microscopy (SEM) image of the 70-70 Si master profile structure, while Figure 1c a set of top view SEM images of the mold for a 70-70 structure, and the corresponding replicated PP surfaces at line-speeds $60 \mathrm{~m} / \mathrm{min}$ and $20 \mathrm{~m} / \mathrm{min}$. Details of the whole fabrication process are given in the Supplementary Information. Foils were produced at line speed ranging from $20 \mathrm{~m} / \mathrm{min}$ to $60 \mathrm{~m} / \mathrm{min}$, while the cooling roller temperature $T_{C}$ was kept at either $50^{\circ} \mathrm{C}$ or $70^{\circ} \mathrm{C}$. The extruder screw speed was kept constant to produce a constant extruder output. This had the implication that the PP film thickness varied linearly with the line-speed from about $15 \mu \mathrm{m}$ at $60 \mathrm{~m} / \mathrm{min}$ to about $45 \mu \mathrm{m}$ at $20 \mathrm{~m} / \mathrm{min}$. Hence, even the thinnest PP film is much thicker than the obtained structure heights. In Figure 1c we show the top view SEM images of respectively the mold surface, and the textured PP surfaces fabricated at line-speeds 60 $\mathrm{m} / \mathrm{min}$ and $20 \mathrm{~m} / \mathrm{min}$. 
We investigated the surface morphology of the fabricated foils by AFM imaging and observed that all surfaces fabricated with higher $T_{C}\left(70^{\circ} \mathrm{C}\right)$ resulted in superior replication of features. Structures fabricated with $T_{C}=50^{\circ} \mathrm{C}$ reached structure heights of only about $10 \%$ of those fabricated at $70^{\circ} \mathrm{C}$. Higher mold temperature makes the semi-crystalline PP less viscous, allowing it to flow more easily into the mold relief. This results in higher nanograss on the replicated foil surface. We will thus only discuss the performance of structures fabricated with $T_{C}=70^{\circ} \mathrm{C}$. For those surfaces, we found that the roughness parameter $R_{Z}$ correlate with the roller line-speed $V_{R} . R_{Z}$ is a standard roughness parameter defined in ISO 4278-1:1997 as the arithmetic mean value of the single roughness depths (the vertical distance between the highest peak and the deepest valley within the sampling length) of consecutive sampling lengths. We found that $R_{Z}$ could be fitted to a sigmoidal function of $V_{R}$. The experimentally obtained $R_{Z}\left(V_{R}\right)$ dependence is shown in Figure $\mathbf{2 a}$ for the $\mathbf{7 0 - 7 0}$ structures together with the fitted sigmoidal function. Figure $\mathbf{2} \mathbf{b}$ illustrates the stretching effect to be discussed below. Figure $\mathbf{2 c}$ shows $3 \mathrm{~d}$ AFM images of the mold and the PP surfaces for the two extreme values of line-speed, while examples of the traces used to determine the $R_{Z}$ values are shown in Figure $2 \mathrm{~d}$. We see that $R_{Z}=(426 \pm 36.6) \mathrm{nm}$ for nanostructures replicated with $V_{R}=20 \mathrm{~m} / \mathrm{min}$, while $R_{Z}=(240 \pm 16.4) \mathrm{nm}$ for $V_{R}=60 \mathrm{~m} / \mathrm{min}$. In order to assess the replication, we measured the $R_{Z}$ value for the Ni mold by employing exactly the same procedure as for the PP samples and arrived at the value $R_{Z}$ $=(218 \pm 9.4) \mathrm{nm}$. We notice that this $R_{Z}$ value for the mold best corresponds to the smallest of values in Figure 2a obtained for high $V_{R}$, while for lower $V_{R}$ we see $R_{Z}$ values exceeding those of the mold by almost $100 \%$. Although the Ni mold has an inverted relief, $R_{Z}$ is expected to match for mold and replica for a true replication. Thus the structure undergoes a tensile plastic deformation at low roller speed. Such stretching of structures has previously been reported for related fabrication technologies. ${ }^{33-35}$ Further, when comparing with the Si master structure (Figure $\mathbf{1 b}$ ), we see a reduction in texture height between Si master and $\mathrm{Ni}$ mold, which is caused by an unavoidable inhomogeneous current distribution at the dense surface of the random nanograss texture during the Ni electroforming process. 

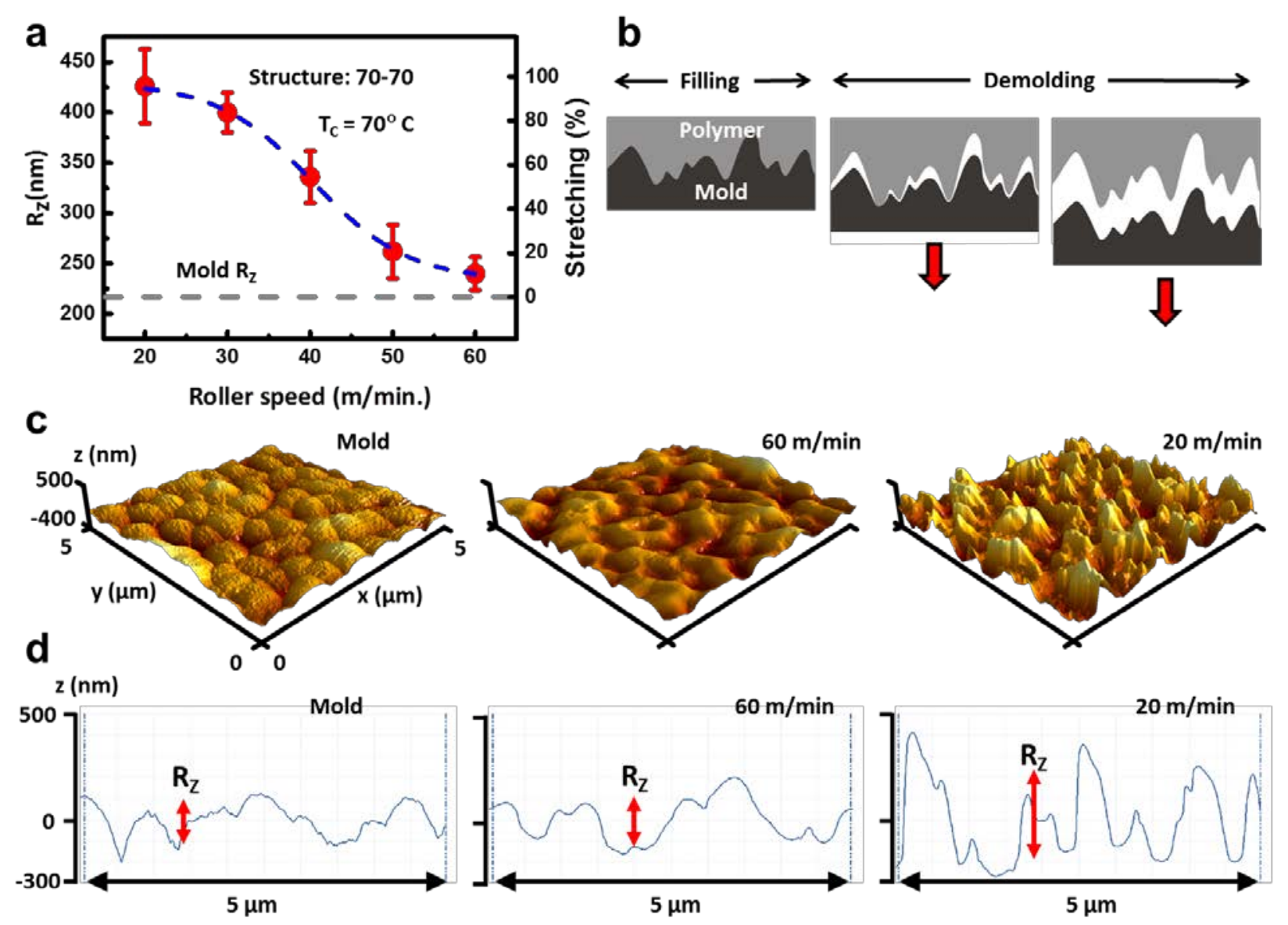

Fig.2 (a) Dependence of the $R_{Z}$ parameter on roller line speed $V_{R}$ for the $70-70$ structure obtained at $70^{\circ} \mathrm{C}$. The values were obtained as the mean values from four (two vertical and two horizontal) traces in the $5 \mu \mathrm{m}$ $x 5 \mu \mathrm{m}$ evaluation area. Error bars are SD $(n=4)$ between the four individual $R_{Z}$ values acquired for each trace. The dotted horizontal line represents the $R_{Z}$ value for the mold, and the right $y$-axis shows the percentage of stretching of the structures compared to the mold value. The fitted function is a sigmoidal Boltzmann function. (b) Schematic of the stretching during the demolding phase of the fabrication. (c) 3D AFM "true surface" data showing a comparison of the mold corresponding to the 70-70 structure, and the corresponding replicated PP surfaces fabricated with the two extreme values of roller speed $20 \mathrm{~m} / \mathrm{min}$ and $60 \mathrm{~m} / \mathrm{min}$ respectively. No axis scaling is applied. (d) Representative 2D AFM scan profiles for the mold and for polymer surfaces fabricated with $20 \mathrm{~m} / \mathrm{min}$, and $60 \mathrm{~m} / \mathrm{min}$. The $R_{Z}$ value is indicated in red for each 
trace, and is obtained as the average of three peak-to-valley distances each from one of three subdivisions of the traces. Y-axis is the same for all traces.

In R2R-EC, a force is exerted on the compliant counter roller to form the so-called nip region where the molten polymer solidifies and adheres to the carrier foil. For a force $F$, applied to the counter roller, the nip pressure is given by: $:^{36,37}$

$$
P_{\text {nip }}=P_{\max } \sqrt{1-\left(\frac{L_{\text {nip }}-2 x}{L_{\text {nip }}}\right)^{2}}
$$

where $P_{\max }=F /\left(\pi W L_{\text {nip }}\right), x$ is the distance along the roller inside the nip from the entrance of polymer melt, $L_{\text {nip }}$ is the length of the nip region, and $W$ is the width of the rollers. The nip length $L_{\text {nip }}$ can be measured for the applied force $F / W=30 \mathrm{kN} / \mathrm{m}$, and was $L_{\text {nip }}=18 \mathrm{~mm}$. Hence, according to Equation 1, the max pressure in the nip is about 24 bar. For a higher line-speed, the polymer will reach further into the nip (larger $x$ ) and experience a higher pressure while being cooled to a given temperature. The residence time for the polymer inside the nip is thus simply given by $L_{\text {nip }} / V_{R}$. Hence, for $V_{R}=60 \mathrm{~m} / \mathrm{min}$, the polymer will spend $18 \mathrm{~ms}$ inside the nip, while for a lower line-speed $(20 \mathrm{~m} / \mathrm{min})$, the polymer will pass through the pressure profile given by Equation 1 over longer time $(54 \mathrm{~ms})$, and simultaneously cool more due to heat conduction. The thicker PP film obtained for higher roller speed is not enough to compensate for the extremely high cooling rate. The semi-crystalline nature of PP plays an important role in this rheological process, as considerable crystallization retardation is expected for the extremely high cooling rate $\left(\sim 10^{7}\right.$ $\mathrm{K} / \mathrm{s}$ ) near the mold. ${ }^{25}$ This leads to texture replication while the polymer is in a supercooled state, and hence does not solidify despite the temperature rapidly drops below the normal solidification temperature. ${ }^{38}$ Regarding the texture stretching effect at low $V_{R}$, the data indicate that almost no stretching occurs, when the polymer is less solidified during the demolding phase of the process, whereas 
the tensile plastic deformation requires a higher degree of solidification that causes the polymer to stick to the mold.

The superhydrophobic effect relies on the so-called Cassie-Baxter ${ }^{39}$ (CB) state, where the surface structures entrap air and thereby form a chemically heterogeneous interface consisting of air and solid to the water. On the macroscopic level, such surfaces are characterized by having WCA above $150^{\circ}$ and small contact angle hysteresis $(\mathrm{CAH}) .^{40}$ In the $\mathrm{CB}$ state, sessile droplets will roll off a superhydrophobic surface for only a small tilt angle $\alpha .{ }^{26}$ Low roll-off angles thus provide a practical measure of the self-cleaning properties of the material. ${ }^{15,41}$ In the Cassie-Baxter model, the apparent WCA $\left(\theta_{e}\right)$ can be expressed by

$$
\cos \theta_{e}=f_{s}\left(\cos \theta_{Y}+1\right)-1
$$

where $\theta_{Y}$ is the Young contact angle, i.e. the contact angle for a smooth surface having the same surface chemistry, whereas $f_{s}=\frac{A_{l s}}{A_{l s}+A_{l g}}$ is the area fraction of the liquid solid interface area to that of the total area of both the liquid solid interface and the liquid gas interface. For the PP used in this study, we have $\theta_{Y}=$ $(100.1 \pm 2.2)^{\circ}$.

To analyze the impact of $R_{Z}$ values on surface functionality we characterized wetting properties of nanopatterned PP foils fabricated with $T_{C}=70^{\circ}$. We conducted systematic contact angle measurements in static and dynamic mode to obtain advancing, receding and static water contact angles (WCA) and roll-off angles $(\alpha)$ for each surface. Since $\alpha$ depends on the droplet volume ${ }^{42}$ all measurements were done using the same droplet volume of $10 \mu \mathrm{l}$. Among the analyzed nanograss textures, texture $70-70$ exhibits the highest contact angles and lowest roll-off angles. For this nanostructure, recorded WCA exceed $150^{\circ}$. Foils replicated with pattern $70-90$ achieved WCA in the range between $140^{\circ}$ to $150^{\circ}$. For surfaces fabricated with the 70-50 morphology we observed the most uneven results. Here WCA ranged between $120^{\circ}$ and $145^{\circ}$ with huge variations. Figure $3 a$ presents an overview of advancing WCA recorded for specific 
replicated texture topographies in the whole range of line-speeds $V_{R}$, while all receding WCA results collected for replicated foils are presented in Figure $\mathbf{3 b}$. In Figure $\mathbf{3 c}$, we summarize the wetting properties for foils with 70-70 replicated texture by plotting the static contact angle data and the roll-off angle data for the 70-70 foils as a function of $R_{Z}$. The recorded values of $\alpha$ descend well below $20^{\circ}$ while the WCA approaches $150^{\circ}$ for the largest values of $R_{Z}$. Surfaces with 70-90 nanostructures resulted in higher $\alpha$, ranging from $22^{\circ}$ to $45^{\circ}$ but for all droplets we eventually observed roll-off when tilting the surface. Only for foils fabricated with the 70-50 nanotexture we observed pinning of water drops, in some cases even for a tilt over $90^{\circ}$.

For structures 70-50, we tested the hypothesis of full wetting, i.e. that sessile droplets rest in the socalled Wenzel state. For this state, the apparent WCA $\theta_{e}$ is given by the Wenzel equation: $\cos \theta_{e}=r \cos \theta_{Y}$, where $r>1$ is the ratio of the real surface area to the projected surface area, and $\theta_{Y}$ is the Young CA for the unstructured foil surface given above. $r$ can readily be obtained from the AFM data (Figure $\mathbf{S 8}$ and Table S3). We see that the Wenzel equation fails to predict the measured WCA data, and we must conclude that even for the 70-50 surfaces, the droplets are in the Cassie-Baxter state. 
a

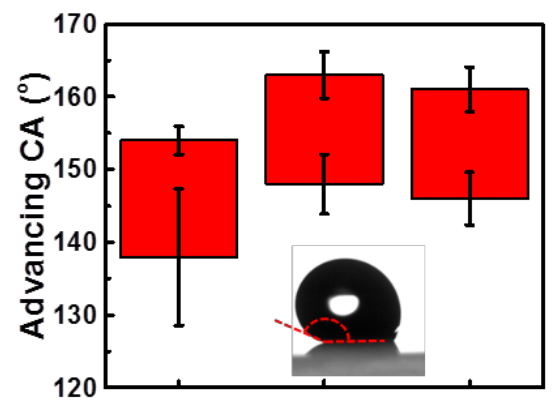

b

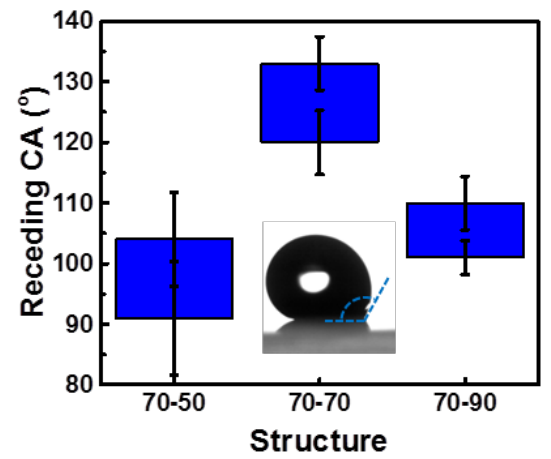

C

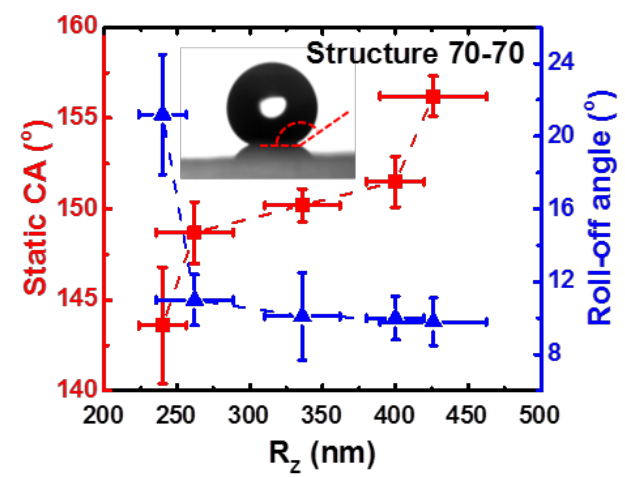

Fig.3 (a) Graph of advancing water CA recorded for specific replicated foils topographies in whole range of line speed $V_{R}$ with the high values corresponding to low line-speed, and low the low values corresponding to high line-speeds. (b) Graph of receding WCA recorded for specific replicated foils topographies in whole range of line speed $V_{R}$. Error bars represent one SD ( $\left.\mathrm{n}=3\right)$ for both figures (a) and (b). (c) Dependence of WCA and roll-off angle $\alpha$ on $R_{Z}$ for foils fabricated with 70-70 nanostructure. The droplet volume used for all measurements was $10 \mu l$.

On the microscopic level, the wetting of such surfaces can be characterized according to the degree of water intrusion into the structures. ${ }^{26,43,44}$ The data in Figure $3 c$ indicate a transition to an enhanced de- 
wetting state roughly at $R_{Z}=325 \mathrm{~nm}$. In a previous publication we found that the wetting properties for superhydrophobic surfaces with cone shaped structure depends on the opening angles of cones, rather than their heights. ${ }^{26}$ However, when cones get stretched, their opening angle decreases. This is shown in Figure 4, where we plot the average opening angle of the structure as a function of the $R_{Z}$ values obtained as a result of different roller line-speeds. The opening angles were derived from the Root Mean Square Gradient, $S d q$ obtained from the AFM data, $S d q=\sqrt{\frac{1}{A} \iint\left((\partial z / \partial x)^{2}+(\partial z / \partial y)^{2}\right) d x d y}$, where $A$ is the sampling area. The average opening angle $\tilde{\alpha}_{o a}$ is then obtained as $\tilde{\alpha}_{o a}=2 \cot ^{-1}(S d q) . \tilde{\alpha}_{o a}$ is not exactly the same as the opening angle of spikes in contact with the water interface, however, the two very likely have the same dependence on $R_{Z}$. We can thus argue that our data are consistent with the wetting properties being determined by either the height or the opening angles of the nanograss cones. A more fundamental argument can be given that most probably it is the opening angle that is the dominating parameter for wetting, since sessile droplets on a superhydrophobic surface will wet only the summits of the structure irrespective of their height.

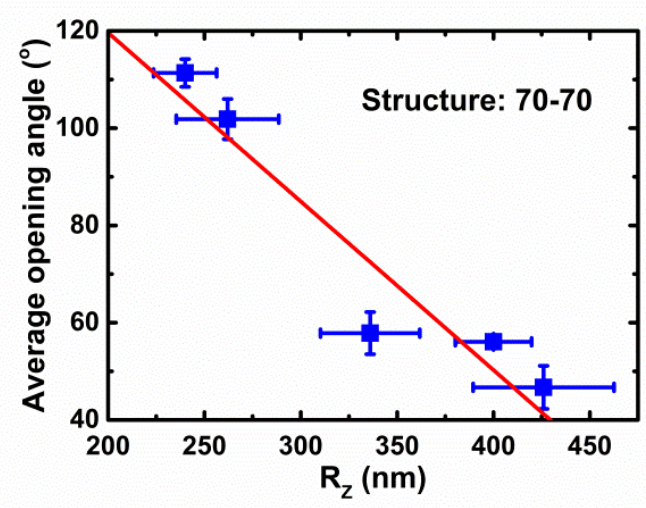

Fig.4 Plot of the average opening angle of cones vs. $R_{Z}$ for foils fabricated with $70-70$ at $T_{C}=70^{\circ} \mathrm{C}$. The dashed red trend line is added to guide the eye. Error bars represent one standard deviation $(n=4)$.

In conclusion, we have demonstrated the superhydrophobic effect for nanostructured polymer surfaces fabricated with a high throughput and low cost novel R2R-EC method.. We obtained the most pronounced 
anti-wetting effect for the highest textures obtained by exploiting a controlled tensile plastic deformation of the nano-texture through systematic adjustment of the cooling roller temperature $T_{C}$ and roller linespeed $V_{R}$. The most stretched structures turned out to have the smallest opening angles and were obtained for the lowest roller speed. This let us to the conclusion that the strongest superhydrophobic effect with WCA approaching $160^{\circ}$, and with roll-off angles below $10^{\circ}$, was obtained for structures having the lowest opening angle resulting from the stretching effect.

\section{Author Contributions}

RT conceived the project. AT, LS, SM, and HP performed the experiments. AT made the data analysis. AT and RT wrote the manuscript with comments from all authors. Approval of the final version was given by all authors.

\section{Acknowledgements}

This work was supported by The Danish Ministry of Higher Education and Science, through an industrial PhD scholarship for SM (grant 1355-00143), and by the Technical University of Denmark, through a special PhD stipend for AT for collaboration with partner universities.

\section{References}

1. Xue, C.-H.; Jia, S.-T.; Zhang, J.; Ma, J.-Z., Large-area fabrication of superhydrophobic surfaces for practical applications: an overview. Science and Technology of Advanced Materials 2010, 11 (3).

2. Yan, Y. Y.; Gao, N.; Barthlott, W., Mimicking natural superhydrophobic surfaces and grasping the wetting process: A review on recent progress in preparing superhydrophobic surfaces. Advances in Colloid and Interface Science 2011, 169 (2), 80-105.

3. Leem, J. W.; Kim, S.; Lee, S. H.; Rogers, J. A.; Kim, E.; Yu, J. S., Efficiency Enhancement of Organic Solar Cells Using Hydrophobic Antireflective Inverted Moth-Eye Nanopatterned PDMS Films. Advanced Energy Materials 2014, 4 (8).

4. Caschera, D.; Cortese, B.; Mezzi, A.; Brucale, M.; Ingo, G. M.; Gigli, G.; Padeletti, G., Ultra Hydrophobic/Superhydrophilic Modified Cotton Textiles through Functionalized Diamond-Like Carbon Coatings for Self-Cleaning Applications. Langmuir 2013, 29 (8), 2775-2783.

5. Anastasiadis, S. H., Development of Functional Polymer Surfaces with Controlled Wettability. Langmuir 2013, 29 (30), 9277-9290.

$6 . \quad \mathrm{Li}, \mathrm{J} . ; \mathrm{Zhu}, \mathrm{J} . ; \mathrm{Gao}, \mathrm{X} ., \mathrm{Bio}-$ Inspired High-Performance Antireflection and Antifogging Polymer Films. Small 2014, 10 (13), 2578-2582.

$7 . \quad$ Kulinich, S. A.; Farzaneh, M., Ice adhesion on super-hydrophobic surfaces. Applied Surface Science 2009, 255 (18), 8153-8157. 
8. Barthlott, W.; Neinhuis, C., Purity of the sacred lotus, or escape from contamination in biological surfaces. Planta 1997, 202 (1), 1-8.

9. Gao, X. F.; Jiang, L., Water-repellent legs of water striders. Nature 2004, 432 (7013), 36-36.

10. Ditsche-Kuru, P.; Schneider, E. S.; Melskotte, J.-E.; Brede, M.; Leder, A.; Barthlott, W.,

Superhydrophobic surfaces of the water bug Notonecta glauca: a model for friction reduction and air retention. Beilstein Journal of Nanotechnology 2011, 2, 137-144.

11. Nosonovsky, M.; Bhushan, B., Biologically inspired surfaces: Broadening the scope of roughness. Advanced Functional Materials 2008, 18 (6), 843-855.

12. Bell, M. S.; Shahraz, A.; Fichthorn, K. A.; Borhan, A., Effects of Hierarchical Surface Roughness on Droplet Contact Angle. Langmuir 2015, 31 (24), 6752-6762.

13. Yeh, K.-Y.; Chen, L.-J.; Chang, J.-Y., Contact angle hysteresis on regular pillar-like hydrophobic surfaces. Langmuir 2008, 24 (1), 245-251.

14. Zhang, L.; Zhou, Z.; Cheng, B.; DeSimone, J. M.; Samulski, E. T., Superhydrophobic behavior of a perfluoropolyether lotus-leaf-like topography. Langmuir 2006, 22 (20), 8576-8580.

15. Larsen, S. T.; Andersen, N. K.; Sogaard, E.; Taboryski, R., Structure Irregularity Impedes Drop Roll-Off at Superhydrophobic Surfaces. Langmuir 2014, 30 (17), 5041-5045.

16. Ahn, S. H.; Guo, L. J., High-speed roll-to-roll nanoimprint lithography on flexible plastic substrates. Advanced Materials 2008, 20 (11), 2044-+.

17. Ahn, S. H.; Guo, L. J., Large-Area Roll-to-Roll and Roll-to-Plate Nanoimprint Lithography: A Step toward High-Throughput Application of Continuous Nanoimprinting. Acs Nano 2009, 3 (8), 2304-2310.

18. Leitgeb, M.; Nees, D.; Ruttloff, S.; Palfinger, U.; Götz, J.; Liska, R.; Belegratis, M. R.; Stadlober, B., Multilength Scale Patterning of Functional Layers by Roll-to-Roll Ultraviolet-Light Assisted Nanoimprint Lithography. ACS Nano 2016, DOI: 10.1021/acsnano.5b07411.

19. John, J.; Tang, Y.; Rothstein, J. P.; Watkins, J. J.; Carter, K. R., Large-area, continuous roll-toroll nanoimprinting with PFPE composite molds. Nanotechnology 2013, 24 (50).

20. Li, Y.; John, J.; Kolewe, K. W.; Schiffman, J. D.; Carter, K. R., Scaling Up Nature: Large Area Flexible Biomimetic Surfaces. Acs Applied Materials \& Interfaces 2015, 7 (42), 23439-23444.

21. Puukilainen, E.; Rasilainen, T.; Suvanto, M.; Pakkanen, T. A., Superhydrophobic polyolefin surfaces: Controlled micro- and nanostructures. Langmuir 2007, 23 (13), 7263-7268.

22. Khan, A.; Li, S.; Tang, X.; Li, W.-D., Nanostructure transfer using cyclic olefin copolymer templates fabricated by thermal nanoimprint lithography. Journal of Vacuum Science \& Technology B 2014, 32 (6).

23. Huovinen, E.; Takkunen, L.; Suvanto, M.; Pakkanen, T. A., Fabrication and quantitative roughness analysis of hierarchical multiscale polymer surface structures. Journal of Micromechanics and Microengineering 2014, 24 (5).

24. Erbil, H. Y.; Demirel, A. L.; Avci, Y.; Mert, O., Transformation of a simple plastic into a superhydrophobic surface. Science 2003, 299 (5611), 1377-1380.

25. Murthy, S.; Matschuk, M.; Huang, Q.; Mandsberg, N. K.; Feidenhans'l, N. A.; Johansen, P.; Christensen, L.; Pranov, H.; Kofod, G.; Pedersen, H. C.; Hassager, O.; Taboryski, R., Fabrication of Nanostructures by Roll-to-Roll Extrusion Coating. Advanced Engineering Materials 2016, 18 (4), 484-489. 26. Schneider, L.; Laustsen, M.; Mandsberg, N.; Taboryski, R., The Influence of Structure Heights and Opening Angles of Micro- and Nanocones on the Macroscopic Surface Wetting Properties. Scientific Reports 2016, 6.

$27 . \quad$ Sainiemi, L.; Jokinen, V.; Shah, A.; Shpak, M.; Aura, S.; Suvanto, P.; Franssila, S., NonReflecting Silicon and Polymer Surfaces by Plasma Etching and Replication. Advanced Materials 2011, 23 (1), 122-+.

28. Dagostino, R.; Flamm, D. L., PLASMA-ETCHING OF SI AND SIO2 IN SF6-O2 MIXTURES. Journal of Applied Physics 1981, 52 (1), 162-167. 
29. Jansen, H.; Deboer, M.; Burger, J.; Legtenberg, R.; Elwenspoek, M., THE BLACK SILICON METHOD .2. THE EFFECT OF MASK MATERIAL AND LOADING ON THE REACTIVE ION ETCHING OF DEEP SILICON TRENCHES. Microelectronic Engineering 1995, 27 (1-4), 475-480.

30. Nguyen, K. N.; Basset, P.; Marty, F.; Leprince-Wang, Y.; Bourouina, T., On the optical and morphological properties of microstructured Black Silicon obtained by cryogenic-enhanced plasma reactive ion etching. Journal of Applied Physics 2013, 113 (19).

31. Yue, Z.; Shen, H.; Jiang, Y., Antireflective nanostructures fabricated by reactive ion etching method on pyramid-structured silicon surface. Applied Surface Science 2013, 271, 402-406.

32. Dorrer, C.; Ruehe, J., Wetting of silicon nanograss: From superhydrophilic to superhydrophobic surfaces. Advanced Materials 2008, 20 (1), 159-+.

33. Roehrig, M.; Mail, M.; Schneider, M.; Louvin, H.; Hopf, A.; Schimmel, T.; Worgull, M.; Hoelscher, H., Nanofur for Biomimetic Applications. Advanced Materials Interfaces 2014, 1 (4).

34. $\quad$ Kavalenka, M. N.; Vuelliers, F.; Lischker, S.; Zeiger, C.; Hopf, A.; Roehrig, M.; Rapp, B. E.; Worgull, M.; Hoelscher, H., Bioinspired Air-Retaining Nanofur for Drag Reduction. Acs Applied Materials \& Interfaces 2015, 7 (20), 10651-10655.

35. Stormonth-Darling, J. M.; Pedersen, R. H.; How, C.; Gadegaard, N., Injection moulding of ultra high aspect ratio nanostructures using coated polymer tooling. Journal of Micromechanics and Microengineering 2014, 24 (7).

36. Sollogoub, C.; Felder, E.; Dernay, Y.; Agassant, J. F.; Deparis, P.; Mikler, N., Thermomechanical analysis and modeling of the extrusion coating process. Polymer Engineering and Science 2008, 48 (8), 1634-1648.

37. Hertz, H., Ueber die Berührung fester elastischer Körper. J. Reine und Angewandte Mathematik 1882, 92.

38. Gradys, A.; Sajkiewicz, P.; Minakov, A. A.; Adamovsky, S.; Schick, C.; Hashimoto, T.; Saijo, K., Crystallization of polypropylene at various cooling rates. Materials Science and Engineering a-Structural Materials Properties Microstructure and Processing 2005, 413, 442-446.

39. Cassie, A. B. D.; Baxter, S., Wettability of porous surfaces. Transactions of the Faraday Society 1944, 40, 0546-0550.

$40 . \quad$ Chen, W.; Fadeev, A. Y.; Hsieh, M. C.; Oner, D.; Youngblood, J.; McCarthy, T. J., Ultrahydrophobic and ultralyophobic surfaces: Some comments and examples. Langmuir 1999, 15 (10), 3395-3399.

41. Feng, X.; Jiang, L., Design and creation of superwetting/antiwetting surfaces. Advanced Materials 2006, 18 (23), 3063-3078.

42. Furmidge, C. G., STUDIES AT PHASE INTERFACES .1. SLIDING OF LIQUID DROPS ON SOLID SURFACES AND A THEORY FOR SPRAY RETENTION. Journal of Colloid Science 1962, 17 (4), 309-\&.

43. Sogaard, E.; Andersen, N. K.; Smistrup, K.; Larsen, S. T.; Sun, L.; Taboryski, R., Study of Transitions between Wetting States on Microcavity Arrays by Optical Transmission Microscopy. Langmuir 2014, 30 (43), 12960-12968.

44. Bottiglione, F.; Di Mundo, R.; Soria, L.; Carbone, G., Wenzel to Cassie Transition in Superhydrophobic Randomly Rough Surfaces. Nanoscience and Nanotechnology Letters 2015, 7 (1), 74-78. 


\section{Key words}

Roll-to-roll, extrusion coating, superhydrophobic, nanotexture, black silicon, polypropylene, crystallization retardation

Table of contents graphic

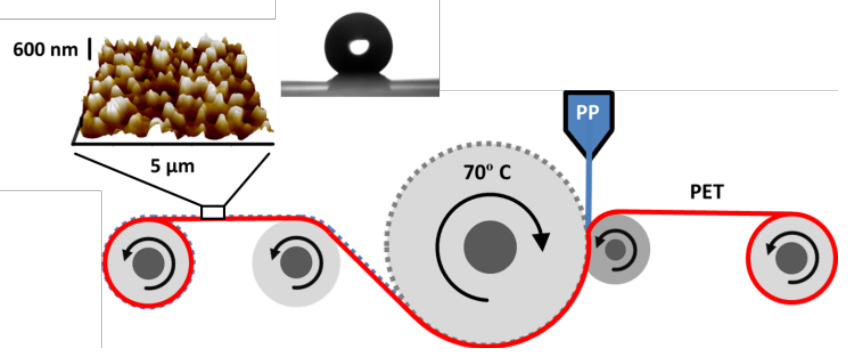

For Table of Contents Only 